\title{
APOIO GERENCIAL NA INCUBAÇÃO DE EMPRESAS DE BASE TECNOLÓGICA: O CASO DA INCUBADORA CISE
}

\author{
MANAGERIAL SUPPORT IN THE INCUBATION OF TECHNOLOGICAL BASED ENTERPRISES: \\ THE CISE INCUBATOR CASE
}

\section{Larissa Florêncio Silva da Costa}

Universidade Federal de Sergipe - UFSE

\author{
Mariana Carla Lima França \\ Universidade Federal de Sergipe - UFSE
}

\section{Rivanda Meira Teixeira}

Universidade Federal de Sergipe - UFSE

\section{RESUMO}

O presente estudo tem como objetivo geral analisar o apoio gerencial oferecido pela incubadora CISE aos empreendimentos de base tecnológica em fase de incubação. Adotou-se a estratégia de pesquisa de estudo de caso único e as evidências foram coletadas através de entrevistas e de fontes documentais. Com base nas evidências encontradas observou-se que a incubadora CISE considera que vem cumprindo seu papel de apoiadora no desenvolvimento gerencial dos seus empreendimentos incubados, no que concerne à estrutura física, assessoria/consultoria e treinamento. No entanto, foram constatadas diferentes percepções por parte dos incubados. Para eles a incubadora vem atendendo parcialmente suas necessidades, especialmente com relação a falta de consultoria/assessoria. Para as estas empresas o apoio na gestão de seus negócios permitiria que o projeto inicial de ingresso fosse desenvolvido e aprimorado e assim seria possível enfocar o aspecto estratégico do negócio e não o operacional.

Palavras-chave: Incubadoras. Empresas de base tecnológica. Apoio gerencial.

\begin{abstract}
The present study has as main objective to analyze the managerial support offered by the CISE incubator to technological based enterprises in the incubation process. It was adopted as research strategy a unique case study and the evidences had been collected through interviews and documentary sources. On the basis of evidences it was observed that CISE incubator considers that is fulfilling its role of supporting the managerial development of its incubated, with respect to the physical structure, managerial support/consultancy and training. However, the incubated have different perceptions. To them the incubator is partially taking care of its needs, especially with regard to consultancy and lack of managerial support. For these enterprises the support in the management of its businesses would allow them to develop and improve them and thus would be possible to focus on strategic aspect and not on its operationalization.
\end{abstract}

Keywords: Incubators. Technological based enterprises. Managerial support. 


\section{INTRODUÇÃO}

Frequentemente as empresas, em qualquer setor que atuem, tem enfrentado dificuldades de penetração e até mesmo de permanência no mercado. Em função disto, tem-se exigido empreendimentos cada vez mais diversificados e inovadores. No entanto, a inovação Isoladamente não proporciona vantagem competitiva se não estiver sendo bem gerenciada. É fato que diante do cenário de concorrência acirrada, as MPEs (micro e pequenas empresas) tem dificuldades para sobreviver. Segundo dados do SEBRAE (2006) - Serviço Brasileiro de Apoio a Micro e Pequenas Empresas, a taxa de mortalidade no Brasil é $49.4 \%$ nas empresas com até dois anos de existência, 56,4\% com até três anos e 59,9\% não sobrevivem além dos quatro anos. Apesar dessas taxas altas, MPEs tem grande importância no mercado, pois empregam mais da metade da população economicamente ativa e são geradoras de quase $38 \%$ da riqueza do país (SEBRAE, 2006).

A atuação de uma incubadora, segundo Boava e Macedo (2004), tem como objetivo proporcionar um ambiente favorável, de tal forma que suas empresas sejam capazes de atuar no mercado de forma competitiva e independente, pois a mortalidade das empresas ocorre muitas vezes em função da falta de conhecimentos básicos sobre conduzir de forma eficaz um negócio (DE SORDI et. al., 2004).

As incubadoras de empresa oferecem apoio e estimulam as pequenas empresas a aumentarem sua competitividade a fim de adaptá-las ao mercado atual. Como explicam Martins, Lima e Xavier (2007), além de oferecer espaço físico e infra-estrutura para o desenvolvimento de novas empresas, propõe-se que uma incubadora também ofereça serviços básicos de consultoria e assessoria, capacitação e network. Os mesmo autores afirmam que um dos grandes desafios é atender necessidades dos empresários e alocar recursos cada vez mais escassos para garantir a sobrevivência no estágio embrionário das empresas e a capacidade de auto-sustentabilidade.

O incentivo das incubadoras atua na combinação de empreendedorismo e know how dos pesquisadores que criam negócios. Ao passo que aspectos gerenciais são aperfeiçoados, esta combinação pode resultar na permanência no mercado (SARAIVA e RODRIGUES, 2004). Renisk (1990, apud MATIAS e LOPES JUNIOR, 2002) afirma que o principal ponto fraco das pequenas empresas é a má administração - responsável por mais de $90 \%$ dos fracassos.

Segundo eles, o fato da administração das pequenas empresas estarem nas mãos de poucas pessoas, e essas, por sua vez, desconhecerem os princípios de administração e seus 3 instrumentos básicos de gestão, causa a sua "morte". Drucker (1991) explica que o pequeno empresário chega a relegar a necessidade de reflexão e planejamento, tentando administrar intuitivamente, quando a própria análise da empresa exige análises constantes.

De acordo com dados da ANPROTEC (2006), Associação Nacional de Entidades Promotoras de Empreendimentos Inovadores, os números de incubadoras em operação no Brasil saltaram de 135 em 2000 para 377 em 2006, estimando-se um valor atual de 400 incubadoras. Outro dado interessante é que a taxa de mortalidade das empresas geradas em incubadoras é de $20 \%$.

Além disso, o MCT - Ministério da Ciência e Tecnologia - divulgou em 2001 que as empresas que passam pelo processo de incubação demonstram maior preocupação com a qualidade e competitividade de seus produtos.

Conforme dados do GEM (2008) - Global Entrepreneurship Monitor - embora as incubadoras tenham apresentado uma rápida expansão nos últimos anos, ainda dispõem de capacidade de 
apoio a empresas de base tecnológica muito aquém das necessidades de um país com as dimensões geográficas e com as sérias fragilidades sociais e econômicas do Brasil. A contribuição da incubadora no processo de gestão das empresas incubadas é fundamental para o enfrentamento dessas instabilidades de mercado. Evidentemente não garante sobrevivência, mas auxilia no processo de resistência.

As Empresas de Base Tecnológica são caracterizadas pela utilização de uma tecnologia considerada inovadora, em que, conforme a ANPROTEC (2006), no processo produtivo o principal insumo é o conhecimento. Para Andino et. al. (2004), normalmente as EBTs são gerenciadas por pessoas que têm um perfil técnico cujas habilidades estão nas áreas de sistemas, química, eletrônica, mecânica, farmácia, entre outras. Isto faz com que os gerentes destas empresas se encontrem melhor preparados no desenvolvimento de seu trabalho na parte técnica ou de produção do que na administrativa, sem estarem aptos para conduzir o negócio.

Desta maneira, esta falta de capacidade gerencial se torna uma das principais razões da elevada taxa de mortalidade das EBTs, de acordo com dados do SEBRAE (2006), sendo um dos fatores críticos para a continuidade e permanência da empresa no mercado. Inserido nesse contexto, o CISE - Centro Incubador de Empresas de Sergipe - atua na incubação de empreendimentos de base tecnológica, e como as demais incubadoras, visa ao desenvolvimento de um ambiente propício a ações empreendedoras ligadas ao setor da tecnologia, através do incentivo à inovação.

0 presente estudo tem como objetivo geral analisar o apoio gerencial oferecido pela incubadora CISE aos empreendimentos de base tecnológica em fase de incubação. Especificamente pretende caracterizar a incubadora CISE; verificar que tipo de apoio gerencial é oferecido; avaliar como as incubadas percebem o apoio gerencial do CISE; identificar qual o tipo de apoio gerencial as incubadas gostariam de ter e identificar a existência de consultoria externa.

\section{EMPRESAS DE BASE TECNOLÓGICA - EBT'S}

No atual contexto, as empresas têm buscado o diferencial estratégico de inovação, pois como asseguram Inácio Junior e Quadros (2006), inovação tecnológica é cada vez mais vista como fator-chave para a competitividade de um país. Para Macedo (2003), a competitividade muda a favor daquelas empresas que apresentam maior habilidade no processo e agilidade no desenvolvimento de novas capacitações.

A inovação é um fator competitivo de relevância como elemento gerador de valor agregado para as empresas atuarem com mais habilidade e agilidade. Mas para que este desenvolvimento exista, as empresas, especificamente as EBTs, necessitam de políticas científico-tecnológicas claras e um adequado programa de estímulo ao setor (ANDINO et al., 2004).

De maneira sucinta, pode-se definir uma EBT como aquela criada a partir de tecnologias desenvolvidas essencialmente dentro da organização onde a empresa se origina (universidade, centro de pesquisa ou empresa privada) (OLIVEIRA FILHO e MENCK, 2008) ou como um empreendimento que tem como insumo conhecimento e informação técnicocientífica (ANPROTEC, 2006).

Segundo Machado, Castro e Silva (2005), a principal característica desse tipo de empresa é a exploração de uma invenção. A definição precisa desse empreendimento é bem difícil, pois, 
conforme os autores Ignácio Júnior e Quadros (2006), na literatura estão presentes definições diferentes ou até mesmo divergentes.

Do ponto de vista de Santos (1984), o surgimento de novas EBT's é fruto de uma ligação científica muito próxima entre empreendedores e as instituições de pesquisa. Esta proximidade pode ser reforçada quando Macedo (2003) explica que o principal insumo das EBT's são os recursos humanos qualificados oriundos das universidades.

Wolffenbüttel, Fracasso e Bignetti (2003) argumentam que, com a finalidade de apoiar o desenvolvimento de EBT's, as incubadoras de empresas têm sido adotadas como uma estratégia para estimular o empreendedorismo no Brasil. Andino et al. (2004), tem um pensamento bastante semelhante, e asseguram que para a contribuição das EBT's para o crescimento do país as mesmas devem sobreviver às contingências impostas pelo mercado, consolidando-se através do tempo, com sucesso. As incubadoras de empresas são um dos meios para que isso se concretize, na medida em que incentivam o empreendedorismo baseado em tecnologia e inovação.

\section{INCUBADORAS}

De acordo com Martinez (2003 apud ANDINO et al., 2004), muitas das EBT's morrem antes da sua consolidação e isso se deve a três fatores: dificuldade de transformar uma tecnologia em um negócio; os pesquisadores possuem habilidades para inovação, mas não possuem habilidades gerenciais por não serem empresários; e o alto grau de investimento que é necessário para esse tipo de empresa.

Freitas e Mendes Junior (2009) asseguram que essas EBT's enfrentam inúmeros problemas que ocasionam elevada taxa de mortalidade. 0 mais freqüente é a capacidade gerencial dos empreendedores. Os mesmos autores explicam que as patologias passam pelas dificuldades e custos da burocracia, a necessidade de captação de recursos financeiros, elevadas taxas de juros, as exigências dos agentes de financiamento, a falta de habilidade para lidar com a concorrência, baixo acesso à tecnologia para inovação e tecnologia da informação e comunicação.

Nesse contexto, as incubadoras de empresas atuam como mecanismos para dar apoio e sustentabilidade no mercado, uma vez que, de acordo com o Programa Nacional de Apoio às Incubadoras de Empresas e Parques Tecnológicos - PNI (MCT, 2000), estas se caracterizam pelo estímulo à criação e o desenvolvimento de micro e pequenas empresas por meio da formação complementar do empreendedor em seus aspectos técnicos e gerenciais.

A título de definição, Bermúdez (2000) explica que incubadora é o termo usado nos dias atuais para descrever um número crescente de grupos de negócios de alta tecnologia que fornecem as facilidades físicas, rede de conhecimentos pessoais, animação, consultorias e um sem número de necessidades e apoios.

A construção de incubadoras de empresas se mostra, assim, essencial, pois fornecem subsídios na fase de preparação dos novos empreendimentos; estrutura e ambiente de apoio; e, favorecem a disseminação de uma cultura empreendedora (LALKAKA, 2002, apud GALLON, LYRIO e ENSSLIN, 2008).

Guimarães, Senhoras e Takeuchi (2003) ressaltam que as incubadoras de empresas são ambientes que propiciam assistência às pequenas empresas em sua fase inicial, mas que após deixá-la, estejam aptas a se manter no mercado. Deve-se compreender que as incubadoras 
deveriam estimular a criação de empresas, algumas das quais, após deixarem a incubadora, podem ser criadoras diretas e indiretas de emprego, com rendimentos e ativos que contribuem para crescimento econômico. (LALKAKA, 2002. v.3, p. 170, tradução nossa).

Hackett e Dilts (2004) evidenciam que, quando se trata do tema "incubadoras", deve-se atentar para cada uma delas em sua totalidade, não simplesmente como um espaço empresarial compartilhado, com infra-estrutura. Deve ser vista como uma rede de indivíduos e organizações, incluindo toda a equipe de gerência, seu conselho administrativo, clientes das empresas e empresários, universidade e membros da comunidade universitária, contatos industriais e demais profissionais, como consultores, investidores de risco e voluntários.

Diante disso, no Brasil a primeira incubadora de empresas surgiu em 1984, na cidade de São Carlos (SP), segundo expõe Macedo (2003). A partir daí, o crescimento vertiginoso do número de incubadoras no Brasil começou a acontecer a partir de 1994, conforme explica Aragão (2005), possivelmente em função da estabilidade econômica promovida pelo Plano Collor. Na Figura 1, é possível verificar a evolução das incubadoras brasileiras.

Figura 01: Evolução do número de Incubadoras no Brasil

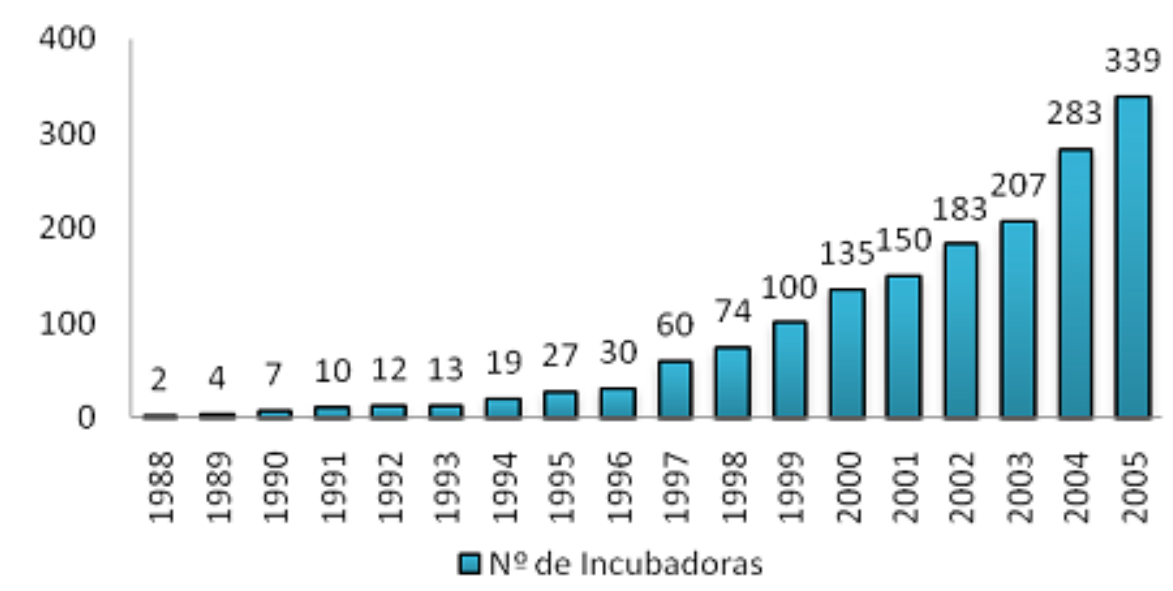

Fonte: Adaptado de ANPROTEC (2005)

0 movimento de incubação brasileiro envolve um total de 5.618 empresas, incluindo as empresas incubadas, as graduadas e as associadas (ANPROTEC, 2005). Na pesquisa de 2005 realizada por esta associação, o número de empresas associadas cresceu $18 \%$ em relação a ultima pesquisa, o que poderia significar uma maior preocupação das incubadoras na ampliação de serviços para o atendimento às empresas além dos limites físicos da incubadora. Os vários serviços oferecidos num programa de incubação foram resumidos no Quadro 1. Nele percebe-se a proposta de apoio não se restringe à estrutura física, mas sim ao apoio na área gerencial. 
Quadro 01: Apoio oferecido na incubadora

\begin{tabular}{|l|l|l|}
\hline \multicolumn{2}{|c|}{ Apoio oferecido } & \multicolumn{1}{c|}{ Descrição } \\
\hline \multirow{2}{*}{$\begin{array}{l}\text { Infra- } \\
\text { estrutura }\end{array}$} & Individualizada & Escritórios e laboratórios especializados; \\
\cline { 2 - 4 } Assessoria & $\begin{array}{l}\text { Humanos e } \\
\text { serviços }\end{array}$ & $\begin{array}{l}\text { Sala de reunião, auditórios, showroom, secretaria, } \\
\text { estacionamento e instalações. }\end{array}$ \\
\hline Serviços & Básicos & $\begin{array}{l}\text { Em atividade de gestão empresarial, gestão da inovação } \\
\text { tecnológica, comercialização de produtos e serviços no } \\
\text { assistência jurídica, captação de recursos, contratos com } \\
\text { financiadores, engenharia da produção e propriedade } \\
\text { intelectual, entre outros. }\end{array}$ \\
\hline Capacitação & Humana & $\begin{array}{l}\text { Telefonia, informática, acesso à internet, fax, impressora, } \\
\text { material de secretaria em geral, manutenção de } \\
\text { equipamentos, endereço postal, endereço de e-mail, } \\
\text { segurança e fotocópias. }\end{array}$ \\
\hline Network & $\begin{array}{l}\text { Treinamento, cursos, participação em eventos, assinatura } \\
\text { de revistas, jornais e publicações. }\end{array}$ \\
\hline
\end{tabular}

Fonte: Moraes (1997), adaptado por Mendes Junior e Freitas (2009)

Segundo Vedovello e Figueiredo (2005), têm sido realizados grandes esforços para a criação e desenvolvimento de incubadoras porque são capazes de melhorar o ambiente competitivo e promover um ambiente mais propício para o desenvolvimento sócio-econômico. Elas têm sido criadas visando oferecer às empresas instalações adequadas e apoio administrativo qualificado com finalidade de gerar empresas bem sucedidas e consolidadas. Em sua natureza de atuação, estimulam o empreendedorismo e divulgam a possibilidade de se criar um negócio próprio com chances reais de êxito (MCT, 2000).

Como descrito por Freitas e Mendes Junior (2009), para cada tipo de empresa que precisa de ajuda há diferentes tipos de incubadoras, classificando-se em: externa, pré-incubação, incubada, graduada e associada. Aqui será dado enfoque às empresas incubadas, sendo aquelas que desenvolvem produtos ou serviços inovadores, abrigadas em incubadoras de empresas, e recebendo todo o apoio técnico, gerencial e financeiro da rede de instituições.

\section{GESTÃO EM INCUBADORAS}

Para alcançar seus objetivos, Stainsack (2003) diz que o processo de gestão de incubadoras envolve recursos físicos, humanos e financeiros. Desse modo, a função da gerência não se limita a executar atividades de apoio, mas coordenar a instituição no sentido de alcançar uma eficaz integração com as empresas incubadas e com os parceiros. Segundo Albert et. al. (2002, apud STAINSACK, 2003), as melhores incubadoras são aquelas que mantêm uma forte relação com o ambiente que as cerca, apresenta uma equipe gerencial eficiente e uma política de propriedade intelectual bem definida e independente.

Os serviços e facilidades - que são intrínsecos ao conceito de incubadora - devem estar disponíveis com eficácia e coerência. A incubadora deve formar sua equipe de gestão, ou pelo menos contratar gerente, e incorporá-lo ao processo já nas etapas iniciais de seu 
planejamento (MCT, 2000).

Em uma análise SWOT elaborada por Dornelas (2000), têm-se como principais fraquezas de uma incubadora: 1) apoio gerencial deficitário às empresas incubadas (assessoria e suporte); 2) ausência de relacionamento contínuo com incubadas e reuniões periódicas; 3) ausência de serviços financeiros que detectem e/ou disponibilizem aporte de capital; e 4) impossibilidade de geração de recursos financeiros que possibilitem auto-suficiência.

Porém, para a eficiência do processo, Aranha et. al. (2002, apud GALLON, et. al. 2009) destacam que informações gerenciais são essenciais aos gestores de incubadoras possam estabelecer estratégias precisas para atingir objetivos organizacionais. Além disso, Stainsack (2003) afirma que esses gestores devem atuar na busca de recursos de que as empresas necessitam, além de promover a integração entre empresas e parceiros promotores. Uma vez que na infra-estrutura oferecida, espera-se um ambiente propício ao desenvolvimento de network, pois se encontram os instrumentos necessários para dinamizar os recursos disponibilizados, favorecendo o aprendizado gerencial dos novos empreendedores (SILVA, 2000).

Frente a uma gestão eficiente, Xavier et al. (2008) afirmam que a incubadora funciona também como uma garantia informal da qualidade oferecida pelas empresas, pois o nome da entidade responsável pela gestão da incubadora ajuda as empresas com uma imagem positiva de seriedade, qualidade e competência. Dessa forma, destaca Maculan (2004), se a sobrevivência das empresas depende da capacidade gerencial e organizacional da incubadora, sua gestão deve atuar no apoio ao desenvolvimento das capacidades das incubadas, fortalecendo também o estabelecimento de parcerias.

Em estudo realizado no Estado de São Paulo, De Sordi et. al. (2004) verificaram que, no que diz respeito ao apoio gerencial, as incubadoras capacitam os empresários na gestão de funcionários, inovação tecnológica e qualidade; serviços de contabilidade e assistência sobre legislação e negociação com clientes e financiadores. Além disso, os autores afirmam que um dos maiores problemas das pequenas empresas paulistas é a forma ineficaz com que conduzem um negócio, e que este problema não estava sendo atacado de maneira suficiente pela incubadora. As empresas participantes estavam, de fato, muito satisfeitas com a estrutura física oferecida, mas o apoio gerencial era falho (DE SORDI et. al, 2004).

Um resultado mais positivo foi percebido no estudo de Saraiva e Rodrigues (2004). Para estes autores, que realizaram sua pesquisa no Estado de Minas Gerais, a qualidade nos processos de incubação das duas incubadoras estudadas foi percebida sem dificuldade. Os proprietários das empresas incubadas eram capacitados por meio de treinamentos e consultoria, cabendo à incubadora captar recursos de fundos setoriais para sua própria manutenção e para a das empresas residentes. Percebeu-se também um expressivo alinhamento estratégico entre os gerentes da incubadora e os empresários.

Boava e Macedo (2004) realizaram um estudo na Incubadora de Base Tecnológica de Londrina e perceberam que os empreendedores, ao significarem sua vivência empreendedora, como abertura de um novo negócio para desenvolvimento e um produto, atribuem à incubadora de empresas o papel de catalisadora do processo de desenvolvimento da ação empreendedora. Os autores concluíram que empreendedorismo independe da ação das incubadoras de empresas, porém esses órgãos podem tornar o desenvolvimento da ação empreendedora mais veloz, efetivo e eficaz. 


\section{METODOLOGIA}

Este estudo pode ser caracterizado quanto aos fins, como exploratório e descritivo. Segundo Vergara (2000), as pesquisas exploratórias são realizadas em áreas na qual há pouco conhecimento sistematizado e acumulado, por sua natureza de sondagem, não comporta hipóteses que, poderão surgir durante ou ao final da pesquisa. Já as pesquisas descritivas buscam descrever sistematicamente um fenômeno ou área de interesse, e essa descrição deve ser detalhada e objetiva (RICHARDSON, 1999).

Para a realização desta pesquisa, adotou-se a o estudo de caso, em que o objetivo é capturar as circunstâncias e condições do dia-a-dia. Para Yin (2001), é o método indicado quando se examinam eventos contemporâneos, mas não se tem controle sobre os comportamentos relevantes envolvidos. Entretanto Vergara (2000) apresenta o estudo de caso como metodologia direcionada para o conhecimento em profundidade de uma determinada problemática e tem como maior limitação a impossibilidade de generalização dos resultados para outras situações.

Quanto à abordagem, tratou-se de um estudo qualitativo. Para Godoy (1995) a pesquisa qualitativa é mais adequada quando se lida com problemas pouco conhecidos e a pesquisa é de cunho exploratório. Além disso, quando o estudo é de caráter descritivo e o que se busca é o entendimento do fenômeno como um todo, na sua complexidade, segundo Vergara (2000), é possível que uma análise qualitativa seja a mais indicada.

As fontes de evidencia utilizadas no estudo de caso foram entrevistas pessoais e análise de documentos da incubadora CISE. 0 instrumento utilizado foi roteiro de entrevista, tendo em vista o caráter qualitativo da pesquisa. Para Richardson (1999) a entrevista possibilita maior interação entre o pesquisador e o pesquisado, por ter caráter inquestionável, de proximidade entre as pessoas e que proporciona as melhores possibilidades de interação. Assim, foram elaborados dois roteiros de entrevistas: um para a equipe gestora da incubadora e outro para as incubadas. No total, foram entrevistadas três pessoas.

Os roteiros das entrevistas foram elaborados com base nas categorias analíticas definidas a partir dos objetivos da pesquisa. As entrevistas foram realizadas pessoalmente no mês de novembro, com agendamento prévio e tiveram duração de aproximadamente vinte minutos.

Para garantir uma maior fidedignidade das informações obtidas, todas as entrevistas foram gravadas e posteriormente transcritas. Vale ressaltar que as duas incubadas têm características diferentes, como: natureza do negócio, tempo de funcionamento na incubadora, formação dos sócios-proprietários.

O caso selecionado foi do CISE - Centro Incubador de Empresas de Sergipe. A escolha de tal incubadora deve-se a vários fatores: vínculo à Universidade Federal de Sergipe, pioneirismo em incubação no estado de Sergipe, número significante de empresas participantes e acessibilidade.

A primeira empresa incubada (1) funciona há um ano e três meses, enquanto a segunda (2) funciona há 3 meses. A formação do sujeito responsável pela gestão da incubada 1 é de Comunicação Social, enquanto da incubada 2 é Administração. A 1 trabalha com assessoria de comunicação e a 2 com consultoria administrativa.

Conforme explica Gil (1999), escolher a entrevista permitiu que fossem obtidas informações acerca do que as pessoas sabem, crêem, esperam, sentem ou desejam, pretendem fazer, fazem 
ou fizeram, bem como acerca das suas explicações ou razões a respeito das coisas precedentes.

As categorias analíticas voltadas para a incubadora deste estudo foram: dificuldades do programa de incubação, apoio gerencial oferecido, acompanhamento de incubadas, consultoria externa, desempenho de incubadas. As categorias voltadas para as incubadas foram: motivação com o programa de incubação, percepção do apoio oferecido, dificuldades enfrentadas, satisfação com a incubadora.

Para o tratamento dos dados foi utilizada a análise de conteúdo de modo que se procurou compreender o conteúdo efetivo da fala dos entrevistados. As informações obtidas foram confrontadas com o referencial teórico, de modo a estabelecer uma ligação entre a teoria e o contexto empírico.

\section{O CASO DO CENTRO INCUBADOR DE EMPRESAS DE SERGIPE-CISE}

O CISE - Centro Incubador de Empresas de Sergipe - está voltado para o estímulo e criação de novos negócios, ligados ao setor de tecnologia. Desde a sua criação, realizou mais de dez seleções de novos empreendimentos e participou de diversos eventos relacionados à inovação tecnológica e empreendedorismo. Idealizado pela Universidade Federal de Sergipe em parceria com outros órgãos, o CISE iniciou suas atividades em dezembro de 2000, visando incubar empresas de base tecnológica, objetivando o crescimento da economia sergipana, a geração de renda e novos negócios.

De acordo com a equipe gestora do CISE, o apoio oferecido contempla: capacitação nos principais aspectos gerenciais; assessoria em elaboração de Plano de Negócios; consultorias/assessorias: empresarial, financeira e contábil e marketing; assessoria em Design; apoio à participação da empresa em eventos com vistas à promoção da empresa e de seu produto; acesso à rede de parceiros da Incubadora; informações para captação de recursos junto à instituições financeiras e/ou investidores; ações de interação entre empresas inovadoras e instituições de ensino e pesquisa; chancela do CISE/UFS conferindo credibilidade à empresa perante o mercado.

Além disso, tem uma estrutura física que proporciona aos incubados: acesso permanente à internet; aparelho de fax; ponto para acesso à linha telefônica; sala de reuniões; dois banheiros (masculino e feminino); estacionamento; vigilância durante todo o dia; limpeza; energia elétrica; água; biblioteca da Rede de Incubadoras de Sergipe - RIS; lanchonete na área comum no Sergipe Parque Tecnológico (onde funciona desde 2006).

Para possibilitar o entendimento dos resultados, os entrevistados serão doravante nominados: E1 (entrevistado da incubadora), E2 (entrevistado da incubada 1), E3 (entrevistado da incubada 2).

Referente às dificuldades do programa de incubação, o sujeito E1 afirmou que os obstáculos enfrentados dizem respeito a dois fatores: escassez de recursos e formação da equipe gestora das empresas incubadas como percebe-se na afirmação:

Quando se opta por iniciar um novo negócio, a maior dificuldade a ser superada é de que forma serão conseguidos recursos financeiros. Então é por isso que no processo de incubação há uma grande dificuldade na captação de dinheiro para dar o apoio às empresas incubadas. 
Além disso, há a dificuldade de lidar com projetos em áreas diferentes, o que foi percebido na fala do entrevistado E1:

É possível perceber que existe a possibilidade de que muitos projetos venham a ser desenvolvidos por pessoas com conhecimentos em áreas específicas e pouco relacionadas com o setor administrativo de uma empresa.

Ainda com relação a essa categoria de análise, foi percebido que as duas incubadas têm visões diferentes. $\mathrm{O}$ entrevistado $\mathrm{E} 2$ afirmou que enfrentou muitas dificuldades, mesmo participando da incubadora, como esclarece: "a pouca experiência com o processo gerencial de uma empresa me deu muitos problemas para enfrentar (...) e não pude me apoiar na incubadora para desenvolver essa área da empresa".

O entrevistado E3, por sua vez, pelo pouco tempo com um negócio, a falta de experiência foi um problema, mas destaca:

A disponibilidade da equipe do CISE nos dá tranqüilidade para recorrer ao auxílio quando necessário. O pessoal é bastante solícito e em todos os momentos que precisamos de algum apoio, eles foram bem ágeis na resolução da questão". Outra dificuldade que esse entrevistado enfrentou concerne aos recursos financeiros para iniciar um negócio, porém "quanto à estrutura para funcionamento da minha empresa o gasto é simbólico, pois o valor cobrado pelo CISE é muito baixo.

No que diz respeito à categoria analítica apoio gerencial oferecido pelo CISE, nota-se que há percepções distintas entre os três entrevistados. E1 afirma que o apoio gerencial oferecido pelo CISE está concentrado em treinamentos e cursos de capacitação. O discurso "O CISE apóia seus incubados em termos de infra-estrutura e apoio operacional. Os treinamentos realizados pela incubadora visam prepará-los para melhor conduzir os seus negócios" pode ser confrontado com o que a incubadora deveria assegurar aos incubados (consultorias/assessorias: empresarial, financeira e contábil e marketing; assessoria em design). Consultoria é atividade de orientação, aconselhamento, fornecimento de subsídios, transferência de conhecimentos, elaboração de relatórios e emissão de parecer acerca de assuntos afins.

No entendimento do entrevistado E1, a consultoria é dada aos incubados na forma de treinamentos. Entretanto, para o entrevistado E2 essa atividade não contenta suas necessidades, como explicita:

Desde que estava fazendo uso das instalações, já sentia a dificuldade que a equipe tinha em nos acompanhar. Além disso, a escassez de recursos financeiros e o pouco apoio dado por instituições parceiras (UFS, SEBRAE) contribuem para o agravamento deste quadro. As vantagens de se ingressar no processo de incubação deveriam estar relacionadas ao relacionamento criado, também, com as entidades de desenvolvimento empresarial, em suas áreas específicas (SESI, SEBRAE, SENAI).

O entrevistado E3 percebeu que, apesar do pouco tempo na incubadora, "não participei, mas há cursos de gerenciamento mais voltados para as necessidades específicas de cada empresa". Outro aspecto verificado é a existência de consultoria externa, uma vez que o entrevistado E1 afirmou que "a maioria das consultorias é externa, pois a equipe é pequena para a quantidade de empresas incubadas e não tem como atender às necessidades de cada uma". 
No que diz concerne ao acompanhamento das incubadas, o respondente E1 afirmou que "periodicamente aplica um questionário de acompanhamento às empresas pré-incubadas e incubadas a fim de identificar suas dificuldades e necessidades". 0 entrevistado E2 explicou que a incubadora possui uma "equipe reduzida que não consegue acompanhar sua empresa,(...) mas isso é justificado por deixar de utilizar as instalações físicas da incubadora, não procurando manter o devido contato com ela". Por sua vez o entrevistado E3, afirma que, fora o programa de ingresso, que já é um critério de avaliação, ainda "não participou de algum acompanhamento por parte da incubadora".

Ressaltando a análise SWOT por Dornelas (2000) as dificuldades principais para uma incubadora são: apoio gerencial, ausência de relacionamento contínuo com as incubadas, ausência de serviços financeiros, impossibilidade de geração de recursos financeiros. Neste caso específico do CISE estas dificuldades são perceptíveis.

Para a expectativa com o programa de incubação, procurou-se verificar que motivos levaram aos empresários procurarem a incubadora e se a expectativa está sendo atendida. 0 entrevistado E2 afirma que está satisfeito, como explica:

Estou satisfeito em partes, pois devo meu desenvolvimento no processo gerencial da minha empresa aos cursos de capacitação. No entanto, a incubadora não consegue acompanhar ou incentivar o desenvolvimento do meu projeto inicial. Há uma maior ocupação com atividades operacionais do que estratégicas".

Quanto ao entrevistado E3, a expectativa tem sido atendida, principalmente no que diz respeito ao "ambiente físico, pois o que nos é oferecido é uma estrutura excelente além da possibilidade de formação de contatos com outras empresas”.

Quanto ao desempenho das suas incubadas, E1 afirmou que a incubadora está satisfeita:

As empresas incubadas do CISE passaram por um processo de seleção onde cada empresa foi avaliada por um comitê técnico e as que hoje estão na incubadora é pelo fato de apresentarem um bom produto/serviço e crescente desenvolvimento, pois aquelas que não possuem bom desempenho certamente já não estão mais na incubadora".

Por fim, quanto à satisfação com a incubadora, o entrevistado E2 assegura que não está satisfeito, pois como comenta:

O apoio gerencial da incubadora deveria ser maior e, assim, a incubada poderia concentrar seus maiores esforços no desenvolvimento do projeto inicialmente proposto, já que contava com a atuação de consultoria/assessoria para dar apoio na área administrativa.

Quanto ao entrevistado E3, percebeu-se satisfação uma vez que afirma:

Temos uma boa impressão, eles são bastante flexíveis e há uma grande preocupação em fornecer condições propícias para atuação das empresas. Bem como instalações físicas e possibilidade enorme de contatos de negócios.

\section{CONCLUSÕES}

Através do programa de incubação de empresas, as incubadoras são responsáveis pelo fomento ao empreendedorismo e aceleração do desenvolvimento das empresas inovadoras 
por meio do oferecimento de suporte, serviços e network. $\mathrm{O}$ objetivo neste artigo foi analisar o apoio gerencial oferecido pela incubadora CISE aos empreendimentos de base tecnológica em fase de incubação.

Com base nas evidências encontradas neste caso, foi verificado que incubadora propõe oferecer o apoio gerencial em formas de consultorias e assessorias, além da realização de treinamentos. A incubadora CISE considera que vem cumprindo seu papel de apoiadora ao desenvolvimento gerencial dos seus empreendimentos incubados, no que concerne à estrutura física, assessorias/consultorias e treinamentos.

No entanto foram constatadas diferentes percepções por parte dos incubados. Para as empresas incubadas a incubadora vem atendendo parcialmente suas necessidades, pois sentem falta de consultoria/assessoria diretas. Para essas empresas o apoio incisivo na gestão de seus negócios permitiria que o projeto de ingresso inicialmente proposto fosse desenvolvido e aprimorado. Para eles, assim seria possível enfocar o aspecto estratégico do negócio e não o operacional. Verificou-se que as empresas incubadas têm necessidades específicas, seja por possuírem diferentes perfis de negócio, seja pela formação de sua equipe de gestão ou pelo tempo de funcionamento. Dessa forma, cada caso deve ser tratado como único e deve ter soluções específicas para o apoio à gestão.

O que foi observado neste caso pôde ser comparado a estudos anteriores. No estudo de De Sordi et. al. (2004), o apoio gerencial também foi percebido como falho, uma vez que as incubadoras não atacavam de forma suficiente a má gestão de suas incubadas. No entanto, Saraiava e Rodrigues (2004) e Boava e Macedo (2004) notaram o papel da incubadora em catalisar o desenvolvimento de suas empresas.

Como sugestão para próximos estudos, propõe-se que seja analisado o alinhamento estratégico entre os gerentes das incubadoras e os incubados. Além disso, que sejam feitos estudos comparativos com as demais incubadoras atuantes no estado de Sergipe, a fim de se verificar os pontos percebidos neste trabalho nas demais incubadoras.

\section{REFERÊNCIAS}

ANDINO, Byron Fabrício Acosta. et al. Avaliação do Processo de Incubação de Empresas em Incubadoras de Base Tecnológica. ENANPAD- Encontro da Associação Nacional de PósGraduação e Pesquisa em Administração, 28, 2004, Curitiba, Anais... Rio de Janeiro: ANPAD, 2004.

ANPROTEC - Associação Nacional de Entidades Promotoras de Empreendimentos Inovadores. Panorama 2005: As Incubadoras de Empresas no Brasil. Disponível em: <http://www.anprotec.org.br>. Acesso em 06 out. 2009.

ARAGÃO, Iracema Machado de. Pós-Incubação de Empresas de Base Tecnológica. São Paulo: USP, 2005. Tese (doutorado em Administração)- Programa de Pós-Graduação em Administração, Faculdade de Economia, Administração e Contabilidade, Universidade de São Paulo, São Paulo, 2005.

BERMÚDEZ, Luís Afonso. Incubadoras de empresas e inovação tecnológica: o caso de Brasília, Revista Parcerias Estratégicas, n. 8, maio de 2000.

BOAVA, Diego Luiz Teixeira; MACEDO, Fernanda Maria Felício. Análise do papel da INTUEL no desenvolvimento da ação empreendedora de empresários incubados. EGEPE- Encontro de 
Estudos sobre Empreendedorismo e Gestão de Pequenas Empresas, 2004. Anais... Curitiba, 2004.

CISE. Centro Incubador de Empresas Estado de Sergipe. Disponível em: $<$ http:www.cise.org.br>. Acesso em: 24 de out. 2009.

DE SORDI, José Osvaldo; SOUZA, José Henrique; TACHIZAWA, Takeshy; BONILHA, Isadora Dória. A Inovação no Processo de Incubação: Viabilidade Para o Sucesso do Empreendedorismo. EGEPE- Encontro de Estudos sobre Empreendedorismo e Gestão de Pequenas Empresas, 5, 2004. Anais... Curitiba, 2004.

DORNELAS, José Carlos de Assis. Análise da Administração Estratégica em uma incubadora de empresas. EGEPE - ENCONTRO DE ESTUDOS SOBRE EMPREENDEDORISMO E GESTÃO DE PEQUENAS EMPRESAS. 1. 2000, Curitiba, Anais... Curitiba, 2000, p. 285-289.

DRUCKER, Peter Ferdinand. A Prática de Administração de empresas. São Paulo: Thomson Pioneira, 1991

FREITAS, Maria do Carmo Duarte; MENDES JUNIOR, Ricardo. Incubação de Empresas. In. Empreendedorismo Tecnológico. Instituto de Engenharia do Paraná: Curitiba, 2009. Cap. 6, p. 154-173.

GALLON, Alessandra Vasconcelos; LYRIO, Maurício Vasconcellos; ENSSLIN, Sandra Rolim. Gerenciamento do Capital Intelectual de uma EBT Incubada: a Contribuição da Metodologia Multicritério de Apoio à Decisão Construtivista. ENANPAD- Encontro da Associação Nacional de Pós-Graduação e Pesquisa em Administração, 32, 2008, Rio de Janeiro, 2008.

GUIMARAES, C. L.; SENHORAS, E. M.; TAKEUCHI, K. P. Ensino, incubação e empresas juniores: As três facetas da Universidade Brasileira inseridas no desenvolvimento do empreendedorismo no século. Congresso Nacional de Empreendedorismo, 1, 2003, Florianópolis-SC. Anais...Congresso Nacional de Empreendedorismo, 2003.

GIL, A. C. Métodos e técnicas de pesquisa social. São Paulo: Atlas, 1999.

GODOY, A. S. Introdução à pesquisa qualitativa e suas possibilidades. Revista de Administração Eletrônica, v. 35, n. 2, mar./abr. 1995. p. 57-63.

HACKETT, S. e DILTS, D. A Systematic Review of Business Incubation Research. Journal of Technology Transfer, v. 29, pg. 55-82. 2004

JUNIOR INÁCIO, Edmundo; QUADROS, Ruy. Proposição de um Novo Método de Seleção de Micro, Pequenas e Médias Empresas de Base Tecnológica (MPEBT). EGEPE - ENCONTRO DE ESTUDOS SOBRE EMPREENDEDORISMO E GESTÃO DE PEQUENAS EMPRESAS. 5. 2006. Anais... Curitiba, 2006.

LALKAKA, R. Tecnology business incubator to assis a inovation based economy. Journal of Change Management, London, v. 3, n. 2, Dec. 2002. 17

MACEDO, Pedro Pereira Delduque de. Avaliação de empresas de base tecnológica candidatas à incubação: o Caso CELTA. 2003. Dissertação (Mestrado em Engenharia da Produção) Universidade Federal de Santa Catarina, Florianópolis, 2003. 
MACHADO, Hilka Pelizza; CASTRO, Silvio Cesar de; SILVA, Marcelo Alves da. Uma abordagem sobre parques tecnológicos e a criação de empresas de base tecnológica. EGEPE - ENCONTRO DE ESTUDOS SOBRE EMPREENDEDORISMO E GESTÃO DE PEQUENAS EMPRESAS. 4. 2005, Curitiba, Anais... Curitiba, 2005, p. 101-110.

MACULAN, A-M. Incubação, capacidade de inovação e aprendizado organizacional das empresas de base tecnológica. Seminário Internacional - Empreendedorismo, Pequenas Empresas e Desenvolvimento Local, 2, Rio de Janeiro, 2004.

MARTINS, G. S.; LIMA, A. A. T. F. C.; SANTOS, Camila Aparecida; OLIVEIRA, Adriel Rodrigues de; CARVALHO, Rosa Maria Miranda Armond; GOMES, Ricardo Corrêa. Incubadoras de Base Tecnológica: um Estudo sobre a Capacitação Gerencial no Processo de Incubação. ENANPAD Encontro da Associação Nacional de Pós-Graduação e Pesquisa em Administração, 29, Brasília-DF, 2005.

MARTINS, Guilherme Silveira ; LIMA, Afonso Augusto T. de F. C. ; XAVIER, Wescley Silva. 0 Papel das Incubadoras de Empresas de Base Tecnológica como Agentes Facilitadores da Interação Universidade/Empresa. SIMPÓSIO DE ADMINISTRAÇÃO DA PRODUÇÃO, LOGÍSTICA E OPERAÇÕES INTERNACIONAIS, 10, 2007, Rio de Janeiro. Anais... SIMPOI. Rio de Janeiro, 2007.

MCT. Manual para implantação de incubadoras de empresas. Brasília: 2000. Disponível em: <http://www.mct.gov.br/setec/setec.htm>. Acesso em: 23 set. 2009.

MATIAS, Alberto Borges; LOPES JÚNIOR, Fábio. Administração financeira nas empresas de pequeno porte. Barueri: Manoele, 2002

OLIVEIRA FILHO, João Bento de; MENCK, André Carlos Martins. Modelos para o Sucesso de PMEs de Base Tecnológica de Origem Acadêmica. ENANPAD - Encontro da Associação Nacional de Pós-Graduação e Pesquisa em Administração, 32, 2008, Rio de Janeiro, 2008.

RICHARDSON, R. J. (Org.). Pesquisa social: métodos e técnicas. São Paulo: Atlas, 1999.

SANTOS, Silvio Aparecido dos. et al. Empreendedorismo de Base Tecnológica: Evolução e Trajetória. 2. ed. Maringá: UNICORPORE. 2005. 190p.

SARAIVA, Luiz Alex Silva; RODRIGUES, Glauciane da Piedade. Incubadoras de Empresas, Empreendedorismo e Desenvolvimento Local em Minas Gerais: Um Estudo de Caso. EGEPE Encontro de Estudos sobre Empreendedorismo e Gestão de Pequenas Empresas, 5, 2004. Anais... Curitiba, 2004.

SEBRAE. Pesquisa GEM 2008. Disponível <http://www.agenciasebrae.com.br/noticia.kmf?noticia=8258159\&canal=289> Acesso em 03 de set. de 2009.

SEBRAE. Serviço Brasileiro de Apoio às Micro e Pequenas Empresas. Disponível em: www.sebrae.com.br. Acesso em: 05 set. de 2009.

SILVA, C. M. de S. e. Inovação e cooperação: o estado das artes no Brasil. Revista do BNDES, v. 7, n. 13, p. 65-88, 2000.

STAINSACK, Cristiane. Estruturação, Organização e Gestão de Incubadoras Tecnológicas. Dissertação de Mestrado do Programa de Pós-Graduação em Tecnologia, Centro Federal de 
Educação Tecnológica do Paraná, Curitiba, 2003.

VEDOVELLO, Conceição; FIGUEIREDO, Paulo N. Incubadora de inovação: Que Nova Espécie é Essa? RAE-eletrônica, São Paulo, v.4, n.1, jan./jul.2005.

VERGARA, S. C. Projetos e relatórios de pesquisa em administração. São Paulo: Atlas, 2000 .

WOLFFENBUTTEL, A. P.; FRACASSO, Edi Madaklena ; BIGNETTI, Luiz Paulo. Avaliação do Potencial de Ingresso no Mercado de Empresas Residentes em uma Incubadora de Base Tecnológica. ENANPAD -Encontro da Associação Nacional de Pós-Graduação e Pesquisa em Administração, 27, 2003, Atibaia, São Paulo, Administração da Ciência e Tecnologia, São Paulo, 2003.

XAVIER, Wescley Silva; MARTINS, Guilherme Silveira; LIMA, Afonso Augusto T. de F. de C. Fortalecendo empreendimentos em TI: qual a contribuição das incubadoras? Journal of Information Systems and Technology Management, v.5, n. 3, P.433-452, 2008.

YIN, R. K. Estudo de caso: planejamento e métodos. 2. ed. Porto Alegre: Bookman, 2001. 